\title{
Study on Removal and Replacement of the Kariba Dam
}

\author{
Bo Chen \\ School of North China Electric Power University, Baoding 071003, China \\ 735303777@qq.com
}

Keywords: Kariba Dam Kriging Interpolation principal component analysis genetic algorithm

\begin{abstract}
The Kariba Dam on the Zambezi River is in dire need of maintenance. This paper is intended to study the strategy of removing and replacing the Kariba Dam.The elevation map of the watershed of Zambezi River is made and rasterized by using Kriging Interpolation. Combining the precipitation and geological condition of the basin, this paper identifies 21 points as candidate points and ranks them with the method of principal component analysis. Then the lowest cost is regarded as the objective function, simultaneously capabilities of water resource utilization and levels of protection for Lake Kariba regarded as the restriction. Eventually, this paper determines the specific number, 18, of dams through the genetic algorithm.
\end{abstract}

\section{Introduction}

The Kariba Dam, completed in the year of 1963 and built to generate hydropower basically, is one of the larger dams in Africa. Recently, a 2015 report by the Institute of Risk Management of South Africa warned that the dam is in dire need of maintenance. This paper provides a solution for one of the options of interest to ZRA, removing the Kariba Dam and replacing it with a series of smaller dams along the Zambezi River.

\section{Locations of new dams}

First of all, the elevation map of the Zambezi River is made and rasterized by using Kriging Interpolation with the purpose of dividing the watershed into small regions as shown in Figure 1; each region is likely to be the site of the dam. Since the primary objective of the Kariba Dam is power generation and flood control, while replacing the Kariba Dam, the hydroelectric energy should be considered primarily. By consulting the literature [1], after analyzing the elevation map and combining the precipitation of the basin, we identified nearly 30 sites with large drop and rich hydroelectric energy. Taking into account another indispensable condition - geological condition in the dam construction, we finally identify 21 points as candidate points.

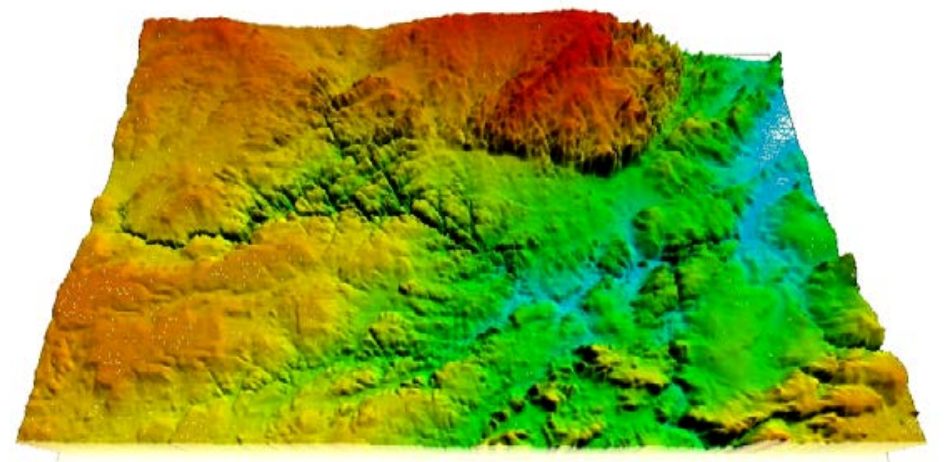

Figure 1 Elevation map

Because each candidate's location and situation are different, we take method of principal component analysis to evaluate and rank these 21 points. The top-ranking represents that it is more conducive to the construction of the dam, that is, it should be given priority. The main factors involved in the assessment and the assessment method are shown in Table 1. The results of principal component analysis are shown in Table 2. 
Table 1 Main factors and assessment method

\begin{tabular}{|c|c|c|c|}
\hline \multicolumn{4}{|c|}{ Assessment method } \\
\hline \multicolumn{2}{|c|}{ Forest restraint factor } & \multicolumn{2}{|c|}{ Whether there is forest nearby and how far } \\
\hline \multicolumn{2}{|c|}{ Hydroelectric factor } & \multicolumn{2}{|c|}{ Amount of water resource } \\
\hline \multicolumn{2}{|c|}{ Urban distance factor } & \multicolumn{2}{|c|}{ Whether there is city nearby and how far } \\
\hline \multicolumn{2}{|c|}{ Dam scale factor } & \multicolumn{2}{|c|}{ Size of the dam } \\
\hline \multicolumn{2}{|c|}{ Farmland irrigation factor } & \multicolumn{2}{|c|}{ Whether there is farmland nearby and how much area } \\
\hline \multicolumn{4}{|c|}{ Table 2 The results of principal component analysis } \\
\hline Number & Characteristic root & Contribution rate & Cumulative contribution rate \\
\hline 1 & 1.6204 & 32.41 & 32.41 \\
\hline 2 & 1.3933 & 27.8659 & 60.28 \\
\hline 3 & 1.0052 & 20.1036 & 80.38 \\
\hline 4 & 0.7109 & 14.2185 & 94.60 \\
\hline 5 & 0.2702 & 5.4038 & 100.00 \\
\hline
\end{tabular}

After analysis, we get the sort order on the candidate points, as shown in Table 3.

Table 3 The sort order on the candidate points

\begin{tabular}{|c|c|c|c|c|c|c|c|c|c|}
\hline \multicolumn{2}{|c|}{ Dam site } & \multirow[b]{2}{*}{$\begin{array}{l}\text { Width } \\
\text { (m) }\end{array}$} & \multirow[b]{2}{*}{$\begin{array}{l}\text { Height } \\
\text { (m) }\end{array}$} & \multirow[b]{2}{*}{$\begin{array}{c}\text { Cit } \\
\mathrm{y}\end{array}$} & \multirow[b]{2}{*}{ Forest } & \multirow[b]{2}{*}{$\underset{\mathrm{d}}{\text { Farmlan }}$} & \multirow[b]{2}{*}{ No } & \multirow[b]{2}{*}{ Ranking } & \multirow[b]{2}{*}{$\begin{array}{c}\text { Evaluation } \\
\text { value }\end{array}$} \\
\hline $\begin{array}{l}\text { south } \\
\text { latitude }\end{array}$ & $\begin{array}{c}\text { east } \\
\text { longitude }\end{array}$ & & & & & & & & \\
\hline 17.98 & 26.07 & 300 & 40 & $\infty$ & $\infty$ & 60 & 1 & 1 & 0.9067 \\
\hline 17.92 & 26.27 & 450 & 80 & $\infty$ & $\infty$ & 0 & 2 & 14 & 0.1883 \\
\hline 17.99 & 26.87 & 600 & 90 & $\infty$ & $\infty$ & 0 & 3 & 5 & 0.5957 \\
\hline 16.82 & 28.76 & 600 & 90 & $\infty$ & $\infty$ & 20 & 4 & 6 & 0.5172 \\
\hline 16.49 & 28.8 & 450 & 70 & 5 & $\infty$ & 0 & 5 & 16 & -0.3002 \\
\hline 15.9 & 28.59 & 300 & 50 & $\infty$ & $\infty$ & 0 & 6 & 15 & -0.2827 \\
\hline 15.64 & 30.02 & 300 & 50 & $\infty$ & $\infty$ & 0 & 7 & 10 & -0.0472 \\
\hline 14.45 & 30.45 & 250 & 40 & $\infty$ & $\infty$ & 0 & 8 & 14 & -0.2471 \\
\hline 16.61 & 34.02 & 550 & 80 & $\infty$ & 5 & 30 & 9 & 3 & 0.6411 \\
\hline 15.85 & 34.74 & 250 & 35 & 5 & $\infty$ & 0 & 10 & 20 & -0.9001 \\
\hline 15.82 & 34.7337 & 150 & 30 & 9 & $\infty$ & 0 & 11 & 21 & -1.1 \\
\hline 15.68 & 34.74 & 400 & 30 & $\infty$ & 3 & 0 & 12 & 11 & -0.0859 \\
\hline 15.87 & 29.09 & 600 & 80 & $\infty$ & 5 & 0 & 13 & 4 & 0.6056 \\
\hline 15.94 & 28.91 & 300 & 45 & $\infty$ & $\infty$ & 80 & 14 & 2 & 0.7799 \\
\hline 17.73 & 34.76 & 300 & 50 & $\infty$ & $\infty$ & 0 & 15 & 17 & -0.5256 \\
\hline 15.59 & 34.75 & 300 & 30 & $\infty$ & $\infty$ & 0 & 16 & 18 & -0.5256 \\
\hline 17.87 & 27.21 & 300 & 40 & $\infty$ & $\infty$ & 0 & 17 & 12 & -0.2042 \\
\hline 17.58 & 27.1 & 300 & 40 & $\infty$ & $\infty$ & 0 & 18 & 13 & -0.2042 \\
\hline 17.11 & 28.03 & 600 & 80 & $\infty$ & 1 & 0 & 19 & 7 & 0.4486 \\
\hline 16.5 & 28.124 & 200 & 30 & 2 & 1 & 50 & 20 & 19 & -0.7089 \\
\hline 17.95 & 27.07 & 600 & 90 & $\infty$ & 2 & 0 & 21 & 8 & 0.4486 \\
\hline
\end{tabular}

Note that the red numbers in the table indicate the parameters of the Shire River. The positive sign of the evaluation value indicates that the benefit is greater than the cost.

\section{Number of new dams}

Because the dam is a project with large scale and large investment, the greater the number of dams is, the greater the ability to modulate water is, the lower the cost of hydropower generation is ${ }^{[2]}$. However, the corresponding costs of overall construction and operation management will increase instead. So there must be an optimal number of dams that can make the total cost of the dam-system minimized. In view of the economic situation in Africa, we propose to use the lowest cost as the objective function, to use the subject of 'the same overall water management capabilities as the existing Kariba Dam while providing the same or greater levels of protection and water management 
options for Lake Kariba' as the restriction. Eventually, we are able to determine the specific number of dams.

$$
\begin{aligned}
& \text { Model Building } \\
& \left\{\begin{array}{l}
\min F(m)=\sum_{i=1}^{m} Q_{i}\left(X_{1}, X_{2}, X_{3}, X_{4}\right)-\sum_{i=1}^{m}\left(B_{i}-C_{i}\right) \cdot n \\
\sum_{i=1}^{m} N_{i}\left(X_{1}\right) \geq N \\
\sum_{i=1}^{m} M_{i}\left(X_{1}\right) \geq M \\
0 \leq m \leq 20
\end{array}\right.
\end{aligned}
$$

\section{Parameter Description}

In this model, the first term in the objective function represents the construction cost; the second term represents net income in the run-time. Constraint 1 indicates that the amount of electricity generated is greater than that of current Kariba Dam; Constraint 2 indicates that the sum of new dam capacity is greater than or equal to the capacity of Kariba Dam; Constraint 3 indicates that the number of dams is between 10 and 20.

\section{Parameter Determination:}

- Determination of $Q_{i}: Q_{i}$ is a regression equation related to dam length, height, installed capacity and construction time. See the specific regression expression :

$Y=-7.0419+0.0143 X_{1}+0.0560 X_{2}+0.0048 X_{3}+0.2467 X_{4}$

- Determination of $B_{i}$ and $C_{i}$ : Bi and $C_{i}$ are the comprehensive evaluation indexes of three major aspects (27 small aspects). It is emphasized that $B_{i}$ and $C_{i}$ represent very comprehensive costs and benefits, so it is reasonable to assume that the difference between $B$ and $C$ is sufficient to represent the water management capacity of Lake Kariba.

- Determination of $n$ : It is known that for small and medium-sized dams, $n$ is usually 10 years.

- Determination of $N_{i}$ : The amount of electricity generated is an amount related to the width and height of the dam, according to the literature [3].

Estimation formula is $N=9.81 \times X_{1} \times 5 \times X_{2}^{2}$

- Determination of $M_{i}: M_{i}=330 X_{2}{ }^{1.55}$.

The model above is a constrained nonlinear programming model. The objective function is a convex function and the feasible region is a nonconvex set. Therefore, it is difficult to achieve the optimal solution by using the general constrained nonlinear programming model (taking SUMT method for example). However, when fmincon () function in Matlab optimization toolbox is used to solve the constrained nonlinear programming model, it may lead to no optimal solution when the value of R-r is small. In order to solve the above constraint nonlinear programming model, the genetic algorithm is adopted. The specific algorithm parameters are shown as follows:

Table 4 The specific algorithm parameters of genetic algorithm

\begin{tabular}{ccc}
\hline Name of parameter & Symbol & Numerical value \\
\hline population size & $M$ & 100 \\
Maximum algebra & $G$ & 5000 \\
crossing-over rate & $p c$ & 1 \\
aberration rate & $P_{m}$ & 0.1 \\
\hline
\end{tabular}

\section{Conclusions}

The result indicates that the optimal number of dams is 18 , in which case the cost is the lowest. Therefore, the first 18 locations above (shown in Table 3) can be selected as the location of the new dam system. 


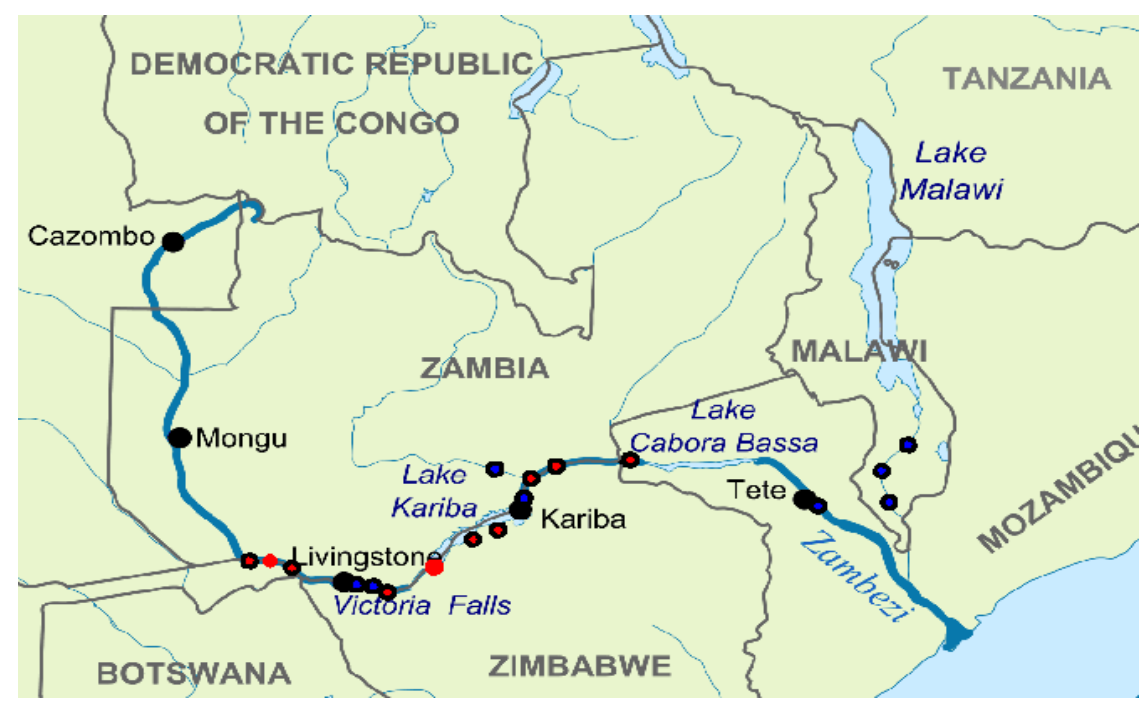

Figure 2 The selected 18 locations

Blue dots indicate dam sites where hydroelectric energy potential is high. Red dots indicate dam sites where hydroelectric energy potential is low. The evaluation of costs of new dam system is shown as Table 5.

Table 5 The evaluation of costs of new dam system

\begin{tabular}{ccccc}
\hline ranking & southern latitude & east longitude & cost(billion) & Duration of recovery cost(year) \\
\hline 1 & 17.98 & 26.07 & 0.08346112 & 0.556407467 \\
2 & 15.94 & 28.91 & 0.11446298 & 0.763086533 \\
3 & 16.61 & 34.02 & 0.73653488 & 4.910232533 \\
4 & 15.87 & 29.09 & 0.81556896 & 5.4371264 \\
5 & 17.99 & 26.87 & 0.89558384 & 5.970558933 \\
6 & 16.82 & 28.76 & 0.89558384 & 5.970558933 \\
7 & 17.11 & 28.03 & 0.81556896 & 5.4371264 \\
8 & 17.95 & 27.07 & 0.89558384 & 5.970558933 \\
9 & 17.92 & 26.27 & 0.57846672 & 3.8564448 \\
10 & 15.64 & 30.02 & 0.145818 & 0.97212 \\
11 & 15.68 & 34.74 & 0.16763584 & 1.117572267 \\
12 & 17.87 & 27.21 & 0.08346112 & 0.556407467 \\
13 & 17.58 & 27.1 & 0.08346112 & 0.556407467 \\
14 & 14.45 & 30.45 & 0.0100776 & 0.067184 \\
15 & 15.9 & 28.59 & 0.145818 & 0.97212 \\
16 & 16.49 & 28.8 & 0.50657452 & 3.377163467 \\
17 & 17.73 & 34.76 & 0.145818 & 0.97212 \\
18 & 15.59 & 34.75 & 0.02251688 & 0.150112533 \\
\hline
\end{tabular}

\section{References}

[1]. REN Xi ,KANG Tian-ke . An Application of Multi-Criteria Analysis Method in Hydropower Project. Journal of Guizhou University 2013, 30(5):31-38

[2]. Kingman, J. F. C. "On continuous time models in the theory of dams." Journal of the Australian Mathematical Society 3.4(1963):480-487.

[3]. WC Study . Kariba Dam Zambia and Zimbabwe. 